\title{
PERCEPCIONES, DECISIONES Y RELACIONES INTERNACIONALES: LOS MÁRGENES OPERATIVOS PERCEPTIVOS ACEPTABLES
}

\author{
Rubén Herrero ${ }^{1}$ \\ UNISCI / Universidad Complutense de Madrid (UCM)
}

\begin{abstract}
Resumen:
El significado de la realidad internacional depende en buena medida de dos aspectos políticopsicológicos, a saber: las decisiones y las percepciones. Las primeras modelan el entorno y las segundas condicionan a las primeras. El concepto de realidad presenta ciertas dificultades a la hora de fijar sus parámetros y coordenadas. Este artículo presenta un concepto que puede contribuir a este último efecto, los márgenes operativos perceptivos aceptables. Al hacerlo, habilitamos un cuerpo teórico para comprender mejor los procesos de percepción y decisión de aquellos que toman las decisiones en el seno del entorno internacional.
\end{abstract}

Palabras clave: Sociedad Internacional, decisiones, percepciones, márgenes operativos perceptivos aceptables.

Title in English: "Perceptions, Decisions and International Relations: Acceptable Perceptive Operating Margins".

\section{Abstract:}

The meaning of international reality depends largely on two political and psychological aspects, namely: decisions and perceptions. The first models the environment and the latter conditions and influences the former. The concept of reality presents certain difficulties to set their parameters and coordinates. This article presents a concept that can contribute to this latter effect, perceptual acceptable operating margins. In doing so, we enable a body of theory for better understanding the processes of perception and decision of those who make decisions on international issues.

Keywords: International Society, Decisions, Perceptions, Acceptable Operating Margins.

\section{Copyright (C) UNISCI, 2012.}

Las opiniones expresadas en estos artículos son propias de sus autores, y no reflejan necesariamente la opinión de UNISCI. The views expressed in these articles are those of the authors, and do not necessarily reflect the views of UNISCI.

\footnotetext{
${ }^{1}$ Prof. Dr. Rubén Herrero de Castro es profesor de Relaciones Internacionales (UCM) e investigador de UNISCI.

Email: rubenherrero@cps.ucm.es.

http://dx.doi.org/10.5209/rev_UNIS.2012.n29.40600
} 


\section{Introducción}

En el escenario global, al igual que en otra suerte de interacciones, las relaciones entre los actores se producen, no entre ellos, tal y como existen en realidad, sino entre imágenes más o menos precisas de los mismos. La manera en que los actores perciben, gestionan y proyectan sus imágenes juega un papel clave en el ámbito de las Relaciones Internacionales.

La palabra clave es percepción, pues sobre ella en una parte destacable, descansan las decisiones $^{2}$ que se toman en los distintos escenarios.

En relación con el concepto de percepción, de acuerdo con Robert Jervis, podemos señalar la existencia de dos entornos ${ }^{3}$ :

a) El entorno operativo: la realidad tal y como existe realmente.

b) El entorno psicológico: la realidad como el actor la percibe.

El tejido de la realidad internacional son las percepciones que se generan en el proceso de percepción, entendiendo por éste, un proceso de integración mediante el cual, los estímulos de la realidad operativa son interpretados por los actores, como resultado de la integración de estos estímulos con las percepciones, imágenes, las ideas y conocimientos (e informaciones) del actor $^{4}$ que percibe.

Este planteamiento nos lleva a analizar otros conceptos clave como: imágenes, ideas, sistema de ideas y proceso de aprendizaje.

Comenzando por el primero y dado que los seres humanos tienden a una comprensión/explicación gráfica del conocimiento, los resultados lógicos de este proceso, son imágenes, que son definidas como las representaciones mentales de las percepciones ${ }^{5}$.

Pero las imágenes no son sólo representaciones vacías, y sí así fuese, éstas sólo serían construcciones lumínicas sin significado alguno. Las imágenes, son estructuras cargadas de contenido, que ayudan a los actores en su interacción con el entorno. Una vez que una imagen es aceptada y establecida será muy difícil de cambiar, dado que los actores son reacios (como veremos más adelante) a alterar la (aparente) estabilidad que le aportan las imágenes que ha aceptado.

Las imágenes, entendidas como el resultado del proceso de percepción, adquieren su relevancia durante el proceso de toma de decisiones a través de tres etapas ${ }^{6}$.

\footnotetext{
${ }^{2}$ Entendiendo por decisión, de forma básica, una elección entre alternativas.

${ }^{3}$ Jervis, Robert (1976): Perception and misperception in International Politics, Princeton University Press, p. 13.

${ }^{4}$ Voss, J.F. and Dorsey, E. (1992): "Perceptions and International Relations", en Singer, Eric and Hudson, Valerie (ed.), Political Psychology and Foreign Policy, Boulder, Westview Press, p. 8.

${ }^{5}$ Las imágenes son un importante factor para entender determinados comportamientos. Por ejemplo, ¿tendrían los ciudadanos y políticos estadounidenses la misma percepción del fenómeno del terrorismo sin la terrible imagen de las Torres Gemelas colapsándose?

${ }^{6}$ Beach, L.R. (1990): Image Theory: Decision Making in personal and organizational contexts, Chichester, West Sussex, England; New York, Wiley, pp.4-7.
} 
a) Contextualización: es éste, un proceso mediante el cual el actor activa sus conocimientos específicos (compuesto de imágenes, información y experiencias) en relación con la situación en cuestión.

b) Adopción de objetivos y planes: relacionados con los objetivos, el actor activará un proceso de contextualización, para establecer objetivos/s, y para decidir si estos son razonables. En relación con los planes, el actor se imagina los planes para conseguir los objetivos propuestos y sus respectivas consecuencias. Para esto último, los actores construyen imágenes de los posibles futuros.

c) Monitorización de progresos: Una vez que el plan ha sido seleccionado, un actor tiene varios cursos de acción alternativos. Si el plan ha sido seleccionado, pero no ejecutado, el actor se trata de proyectar imágenes más precisas sobre lo que sucederá. Si el plan se ha implementado, el actor procede a comparar las imágenes que recibe/percibe con las imaginadas/esperadas antes de la puesta en marcha del plan.

A partir de estas etapas, cabe plantear una definición complementaria de imágenes, como estructuras cognitivas que resumen todo el conocimiento del actor, sobre qué, por qué y cómo deben/deberían establecerse los objetivos y alcanzar los resultados deseados ${ }^{7}$.

Vinculados con estas tres etapas y siguiendo con la relación entre las imágenes y la toma de decisiones, podemos identificar tres tipos de imágenes, relacionadas con la toma de decisión en política exterior ${ }^{8}$.

a) Imágenes valor: estas se relacionan con las normas, valores, ideas y creencias que representan los principios. La pregunta que estas imágenes tratan de responder es -ipor qué?-. Dentro de este tipo de imágenes, hay que distinguir entre las creencias centrales y periféricas. Las primeras, son el resultado de las propias experiencias de los actores, mostrando resistencia al cambio y ejercen una poderosa influencia sobre otros principios e ideas. Las segundas, son más maleables y se utilizan para situaciones específicas. Otra distinción que hay que mencionar, es la que existe entre los principios primarios y secundarios, cuyas características son más o menos equivalentes a las de las creencias centrales y periféricas. La principal diferencia entre las creencias y principios, es que los principios tienen un carácter imperativo y prescriben lo que debe y no debe hacerse ${ }^{9}$.

b) Imágenes trayectoria: estas configuran la agenda del actor hacia el futuro, ya que se centran en sus objetivos. La pregunta que estas imágenes tratan de responder es, -¿qué?. De dos maneras.

c) En primer lugar, ¿qué quiere conseguir el actor?. Y en segundo lugar, ¿qué espera el actor que sucederá?

\footnotetext{
${ }^{7}$ Ibid., p.4.

${ }^{8}$ Ibid., pp.8-29.

9 Es importante señalar que el término "principio" por sí mismo no está relacionado con la bondad. Los principios pueden ser bondadosos o perversos. Estos últimos también existen y por supuesto, motivan acciones y decisiones.
} 
d) Imágenes estratégicas. Estas se centran en los diversos planes diseñados. Este tipo de imágenes representan la perspectiva global del actor y las diferentes las líneas temporales, en los que los diversos planes se ejecutan simultáneamente. En relación con este tipo de imágenes se pueden distinguir cuatro conceptos adicionales. En primer lugar, planes, que pueden definirse como estrategias abstractas que anticipan una secuencia de actividades. Al igual que sucedía con las imágenes estratégicas, el actor despliega/desarrolla mentalmente los planes, mostrando el éxito o el fracaso de los mismos. Por ejemplo, si las imágenes muestran el fracaso del plan, éste será abandonado. Los planes deben ser construidos sobre la base de conocimiento del pasado (historia), las características del presente (la situación) y sobre las previsiones/expectativas respecto al futuro. En segundo lugar, tácticas, que representan comportamientos específicos que surgen de los planes abstractos. Los efectos de las tácticas, serán mucho mejores si son flexibles, admitiendo un cierto grado de cambio, especialmente si van a ser implementadas en entornos complejos y cambiantes. En tercer lugar, políticas, que son planes pre-diseñados que los actores pueden usar cuando se identifique un contexto como similar a otros que han ocurrido antes. Una vez más la flexibilidad debe incorporarse porque es muy poco probable que se dé una repetición exacta de cualquier situación o contexto pasado, lo que significa que las políticas no se pueden aplicar exactamente tal y como se hizo en el pasado. Y en cuarto lugar, previsiones, que entran en juego cuando existen diversos planes de acción y el actor tiene que prever el/los resultado/s de esos planes. Esto requiere la capacidad de construir futuros posibles. El actor tiene que "ver" los aspectos/factores controlables e incontrolables, asociados a los diversos planes. Luego, al comparar el futuro esperado con el futuro deseado, el actor debe ser capaz de estimar la viabilidad de los diferentes planes. Y una vez que el plan o los planes seleccionados se aplican / ejecutado, el actor implementará un proceso de evaluación para comprobar el grado de satisfacción y progresión hacia los objetivos propuestos.

Profundizando en la relación entre las imágenes, las percepciones y las decisiones, y de acuerdo con la introducción que planteamos a este artículo, tenemos que referirnos ahora a dos importantes conceptos más: las ideas y el sistema de ideas.

De acuerdo con Voss y Dorsey, una idea es la información que un actor tiene sobre otros actores, asuntos generales y materias específicas ${ }^{10}$. Estamos de acuerdo con John Elster cuando el afirma que las ideas tienen su origen en la doble necesidad del actor de dar un significado al entorno que le rodea así como disponer de justificaciones para sus actos y decisiones ${ }^{11}$. A veces esta necesidad política y psicológica provoca que el actor no busque la idea correcta sino aquella que coincide, responde y justifica sus percepciones y acciones.

Las ideas en el vacío no tienen sentido, así que para mejorar su relación con el entorno el actor integrará todas sus ideas en un sistema de ideas. Este puede ser definido como una perspectiva general compuesta por las imágenes del pasado, el presente y del futuro, así como todo el conocimiento organizado que el actor tiene sobre si mismo, los otros actores y el entorno que le rodea. En palabras de Ole Holsti un sistema de ideas puede ser concebido como una lente a través de la cual toda la información relevante es percibida ${ }^{12}$. Por lo tanto,

\footnotetext{
${ }^{10}$ Voss, J.F. and Dorsey, E., op. cit., p.11.

${ }^{11}$ Elster, Jon (1983): Political Psychology, Cambridge University Press, p. 14.

${ }^{12}$ Holsti, Ole (1968): "Cognitive dynamics and images of the enemy", in Farell, John and Smith, Asa P.: Image and reality in world politics, New York, Columbia University Press, p. 18.
} 
el sistema de ideas orienta al actor y contribuye a motivar sus decisiones hacia el entorno. De esta forma podemos establecer una relación bidireccional entre imágenes y sistema de ideas. A saber, los actores usan las imágenes para tomar decisiones, pero en el proceso de formar imágenes, el sistema de ideas del actor jugara un papel clave. Y una vez una imagen es formada, si es considerada relevante, pasa a formar parte del sistema de ideas.

Las imágenes son entonces una sub-parte esencial de un todo que es el sistema de ideas cuyas principales funciones son tres. La primera, organizar el conocimiento específico y general del actor. La segunda, organizar las imágenes y la tercera, establecer los objetivos y el orden de preferencia. Por así decirlo, de acuerdo con nuestras percepciones cuyo origen radicamos en el sistema de ideas, sustantivamos nuestras decisiones. Esto es, una vez que los actores tienen la información, las percepciones e imágenes que ellos consideran que necesitan sobre el entorno, las decisiones se tomarán, como una forma de influir, modificar, e incluso transformarlo.

Pero obviamente no todo es intangible en el marco del sistema de ideas, también hay elementos objetivos como los conocimientos y la información, a los que nos referimos a continuación.

Además de la repercusión de las imágenes, hay otros factores, tales como el proceso de aprendizaje y el proceso de adquisición de la información, que ayudan a los actores en las tareas de formar percepciones y tomar decisiones.

El objetivo del proceso de aprendizaje es la adquisición de conocimiento y asimilación de experiencias que, junto con las percepciones, imágenes, ideas y emociones, generarán para los actores, los modelos que les ayuden, primero a comprender y luego a tomar decisiones. Todos estos factores, además de aquello que ha sido aprendido, experimentado, vivido, hacen posible la comprensión, adaptación e interacción con el entorno y contribuyen a explicar las percepciones, decisiones y los posibles cambios que podrían surgir en relación con estos dos últimos términos.

Etheredge se refiere a dos elementos claves que apoyan el proceso de aprendizaje ${ }^{13}$ : la inteligencia primera, en el sentido de obtener una perspectiva más exacta de la realidad y ser capaz de utilizarlo en la toma de decisiones y, en segundo lugar, la eficacia o la habilidad de alcanzar un mayor grado de éxito en aquello propuesto.

En relación con el aprendizaje e información, en el contexto de las Relaciones Internacionales, encontramos dos comportamientos que darán al actor más elementos a considerar: las señales y los índices ${ }^{14}$.

Las primeras, son acciones que indican expectativas de comportamiento, cuyo significado se establece como resultado del entendimiento mutuo y tácito (es decir, un discurso, la asistencia a una reunión, un símbolo, etc) y no conllevan una utilización de recursos considerable.

Los segundos, son también acciones de expectativas de conducta, que incluyen algunas pruebas tangibles, de que un actor se comportará como expresa que hará, ya que esas pruebas

\footnotetext{
${ }^{13}$ Etheredge, L.S. (1985): Can Governments learn?, New York, Pergamon Press, cited by Voss J.F. and Dorsey E. in Singer, Eric and Hudson, Valerie (ed.), op. cit., p. 21.

${ }^{14}$ Jervis, Robert (1970): The logic of images in International Relations, Princeton, N.J., Princeton University Press, p.5.
} 
están intrínsecamente vinculadas a las intenciones del actor que los emite y comportan empleo mayor o menor de recursos (por ejemplo, la firma de un tratado, un despliegue militar).

Si sumamos los argumentos desarrollados hasta el momento, el resultado podríamos plantearlo en una pregunta: ¿por qué los actores tienen diferentes percepciones y toman decisiones diferentes cuando están expuestos a una misma situación?

Para explicar este fenómeno hay que considerar varias causas posibles.

En primer lugar, podemos encontrar en la Historia algunas respuestas acerca de la construcción y evolución de las percepciones que guían el comportamiento y motivan (en grado variable) las decisiones. Al revisar los procesos de decisión, tenemos que considerar el concepto del proceso de aprendizaje, de acuerdo a la definición aportada antes. Así, situaciones históricas específicas, experiencias y/o lecciones derivadas de la historia, pueden dar lugar a las ideas y percepciones que más adelante, contribuirán a fundamentar las decisiones tomadas.

En segundo lugar, los actores pueden tener diferentes objetivos. De tal forma un mismo escenario puede provocar percepciones diferentes y por consiguiente decisiones y planes diferentes para lograr los resultados deseados. En tercer lugar, los agentes pueden desarrollar diferentes imágenes de la escena internacional, debido a diferentes conjuntos de percepciones, imágenes e ideas, que resultan en diversos y diferentes sistemas de ideas. Por ejemplo, cuando el líder de un régimen religioso examina/percibe la realidad a través de la lente de su sistema de ideas fuertemente influenciado por sus creencias e ideas religiosas. Obviamente las imágenes resultantes de este proceso serán muy diferentes de las que pueda obtener del mismo entorno el líder de un régimen democrático.

En cuarto lugar, el desarrollo del proceso de información que motiva las decisiones posteriores, influencia de forma significativa las percepciones del actor y puede explicar diferencias en las mismas. En relación con la información, es importante, la cantidad, la calidad y el origen de la misma, que el actor está recibiendo. De igual importancia es también la información que el líder no está recibiendo. El buen funcionamiento de los servicios de información e inteligencia, además de la colisión de los intereses de las diferentes organizaciones involucradas, juegan un papel muy importante en la gestión de la información. Una pregunta relevante referida a la información, que podríamos plantear y cuya respuesta sería muy interesante conocer, a la hora de examinar y entender el (diferente) comportamiento de varios actores hacia el mismo entorno, sería - ¿qué información tienen a su disposición, y cómo la están usando?-.

En quinto lugar, los factores políticos, juegan un papel importante a la hora de percibir, por ejemplo el sistema político. Es lógico pensar que las percepciones de líderes de actores democráticos, puedan variar de las de actores no democráticos, ya que ambos tipos de actor, manejan factores políticos y morales dispares. En relación con las diferencias sobre las percepciones y decisiones entre actores democráticos, el acento podría ser puesto en la naturaleza y características de sus sistemas políticos. Así que las diferentes culturas, procesos políticos y procedimientos de toma de decisiones, pueden llevar a decisiones diferentes.

En sexto lugar, la personalidad de quién toma las decisiones y la de los involucrados en el desarrollo y la aplicación de la política exterior puede influir en la generación de percepciones no similares y desembocar en decisiones y en pautas distintas de acción. La personalidad puede ser definida como la forma en que los individuos son diferentes unos de 
otros $^{15}$. La influencia de este elemento es clave, a la hora de explicar el comportamiento político. Esta afirmación se basa en la premisa de que ningún comportamiento político existe en el vacío, sino que sucede en un entorno específico, y por tanto no existe el comportamiento político independientemente de una persona ${ }^{16}$. Por ello, la existencia de diferentes personalidades puede contribuir a una explicación de las diferentes decisiones relacionadas con el mismo entorno.

Por último, es evidente que la percepción entre los grupos de actores debe ser considerada en relación con los objetivos, metas, intereses y medios de los actores. Incluso cuando los objetivos son compartidos entre diversos actores, estos pueden tener distintos medios para lograr sus objetivos. Ello producirá las decisiones pueden variar de actor a otro, de acuerdo con sus capacidades e inclinaciones para actuar en determinadas circunstancias. Por ejemplo, en el caso del terrorismo islámico, todos los actores legales, coinciden en que es un problema muy importante que tiene que ser solucionado. La diferencia es dónde y cómo, y este por ejemplo ha sido un elemento diferenciador importante entre las decisiones adoptadas por Estados Unidos y algunos de sus aliados europeos.

\section{Márgenes operativos perceptivos aceptables: realidad operativa, percepciones y percepciones erróneas}

Una vez expuesto de forma breve un cuerpo teórico que relaciona las decisiones con las percepciones, cabe plantearse otra pregunta: ¿Cómo pueden los actores relacionarse eficazmente entre sí, dadas las múltiples y posibles percepciones de una misma realidad?

La respuesta, es que los actores tienden a operar dentro de lo que nosotros definimos como márgenes operativos perceptivos aceptables. Es decir, la mayor parte de las percepciones fluctúan dentro de un perímetro aceptable y operativo, para la mayoría de los actores. Las percepciones que se producen en ese perímetro pueden variar de unos actores a otros, pero tienen un contenido similar (y aceptable) que permite a los demás actores conocer con cierto grado de certeza y entender (aunque no compartan), las percepciones e imágenes que los otros actores están percibiendo.

No obstante y dentro de los límites de estos márgenes, habrá actores que perciban con mayor calidad que otros, por ejemplo por contar con mejor información. Y ello debería repercutir, en una mejor calidad de las decisiones, si se implementan de forma eficiente los medios necesarios.

Lo márgenes perceptivos, constituyen una suerte de realidad operativa y amplia, ante la imposibilidad de dictaminar exactamente qué realidad existe.

En el marco de todo proceso de toma de decisiones, se opera con el hecho de la percepción. Pero ello en sí mismo, encierra, el riesgo de incurrir en una mala interpretación o percepción errónea de los estímulos emitidos desde el escenario de juego.

\footnotetext{
${ }^{15}$ Greenstein, Fred, I, (1971): “The study of personality and politics: overall considerations”, in Greenstein, Fred I. y Lerner, Michael: A source book for the study of personality and politics, Chicago, Markham Political Science Series, p. 16.

${ }^{16}$ Barner-Barry, Carol y Rosenwein, Robert (1985): Psychological perspectives on politics, Englewood Cliffs, N.J., Prentice Hall, p. 19.
} 
Hablamos de percepciones erróneas para referirnos a aquellas que se han originado sobre la base de información no objetiva y colocan por tanto al actor fuera de los márgenes operativos perceptivos aceptables. Cuanto mayor sea la distancia que le separa de estos, peor serán sus efectos sobre sus decisiones, ya que el decisor percibe y opera sobre una realidad que sólo existe para él en su espacio mental y cognitivo. Por así decirlo, están actuando de acuerdo a la realidad inventada ${ }^{17}$ que han aceptado (como real) y/o que han construido.

Uno de los fenómenos de percepción errónea más importantes que pudiera surgir en el escenario internacional es la dinámica político-psicológica denominada wishful thinking. Este es un proceso psicológico y político por el que el actor establece una relación sustancialmente subjetiva, ilusoria y ficticia entre sus deseos y la realidad. Piensa por ello, que opera en un mundo que es benigno respecto a la protección de sus intereses y valores ${ }^{18}$. Ello puede suceder, cuando el actor reacciona rápidamente o esta ansioso de relacionar hechos y expectativas. Entonces porciones relevantes de información pueden perderse. Hay en el individuo, una tendencia a rechazar y/o ignorar información relevante y objetiva que no encaja con las ideas previas del actor, mientras que éste aceptara porciones incluso débilmente argumentadas por el hecho de adecuarse o encajar con sus expectativas, esperanzas y deseos. Si este es el caso, surgirá el fenómeno antes mencionado de wishful thinking, por el cual el actor reduce las consecuencias negativas de sus decisiones porque esta percibiendo una realidad que coincide con sus imágenes previas, valores e intereses ${ }^{19}$. Como señala Robert Jervis "desafortunadamente una vez hemos establecido una idea sobre como funciona el mundo o disponemos de una imagen de otros actores en nuestra mente, tendemos a no examinar nueva información o reexaminar información antigua de una forma imparcial. Por el contrario, nosotros somos proclives a identificar y asimilar la nueva información con nuestra ideas previas o preexistentes contribuyendo a reforzarlas ${ }^{20}$.

Por ello, los actores que toman las decisiones deben mantenerse dentro de los márgenes operativos perceptivos, donde también podrán tener percepciones erróneas, pero indudablemente sus efectos negativos serán menores que si tales percepciones se producen más allá de los márgenes que hemos definido y aportado.

Lo normal, será que la mayoría de las percepciones sean acertadas (en grado variable), por la naturaleza legal de la mayoría de los jugadores ${ }^{21}$ y por ello, son viables las relaciones entre la mayoría de los actores que operan en el escenario global. Pero, como alertábamos antes, hay un riesgo de percibir de forma errónea, que los actores deben conocer y evitar en todos los casos, pues sólo percibiendo y actuando en una realidad operativa, estarán en disposición de obtener unos resultados satisfactorios.

\footnotetext{
${ }^{17}$ El concepto de "realidad inventada" es explicado y desarrollado en, Herrero de Castro, Rubén (2006): La realidad inventada. Percepciones y proceso de toma de decisiones en Política Exterior, Villaviciosa de Odón, Madrid, Plaza y Valdés.

${ }^{18}$ Jervis, "Perception and misperception...", op. cit., p. 366.

${ }^{19}$ Ibid., Idem.

${ }^{20}$ Jervis, Robert, "Foreword", in Herrero de Castro, Rubén, La realidad inventada. Percepciones y proceso de toma de decisiones en Política Exterior, Plaza y Valdés, 2006, p. 15.

${ }^{21}$ Entendemos por jugador legal, aquel que sigue las reglas de la sociedad internacional y observa el estado de derecho en su entorno doméstico. Principalmente serían actores legales, las democracias parlamentarias con economías de mercado y la práctica totalidad de organismos internacionales participados por estos estados, aunque pueden darse excepciones, especialmente en cuanto a la naturaleza del régimen político. Individuos con notoriedad nacional e internacional, así como muchas de las organizaciones no gubernamentales existentes y otras de carácter diverso, pueden ser también jugadores legales, siempre y cuando observen y cumplan las reglas establecidas.
} 